\title{
Extrusion Processing of Amaranth and Quinoa into Gluten-Free Snack Foods for Celiac and Gluten-Free Diets
}

\author{
Caitlin Gearhart ${ }^{1} \&$ Kurt A. Rosentrater ${ }^{1}$ \\ ${ }^{1}$ Agricultural and Biosystems Engineering, Food Science and Human Nutrition, Iowa State University, United \\ States \\ Correspondence: Kurt A. Rosentrater, Agricultural and Biosystems Engineering, Food Science and Human \\ Nutrition, Iowa State University, United States. E-mail: karosent@iastate.edu
}

Received: July 28, $2017 \quad$ Accepted: August 24, $2017 \quad$ Online Published: August 30, 2017

doi:10.5539/jfr.v6n5p107

URL: https://doi.org/10.5539/jfr.v6n5p107

\begin{abstract}
Because of the growth of gluten intolerance and Celiac disease, there is growing interest in development of gluten-free foods. Beyond just being gluten-free, such foods can also have other positive nutritional benefits to human health. Extrusion processing is commonly used to produce a wide variety of human food products. Gluten-free grains can be a processing challenge, however, due to lack of proper binding, which can lead to poor quality food products. This research explores how extrusion parameters impacted the quality of amaranth- and quinoa-based extrudates. The specific objectives of this project included extruding each of the grains, then measuring extrudate properties, such as color, unit density, expansion ratio, and durability. Both the quinoa and amaranth were extruded as raw grain, as well as ground to $2 \mathrm{~mm}$ and $1 \mathrm{~mm}$ particle sizes. Other experimental conditions included moisture contents of $20 \%$ and $40 \%$ (d.b.), and extruder screw speeds of $50 \mathrm{rpm}$ and $100 \mathrm{rpm}$. All treatments were successfully extruded, and all extrudates had high quality attributes, making this the first time either quinoa or amaranth was extruded without any binding ingredients. This study provides information useful for commercial scale-up.
\end{abstract}

Keywords: extrusion, grains, amaranth, quinoa, gluten-free

\section{Introduction}

Extrusion is a process that produces a variety of foods from fundamental ingredients. This process utilizes an extruder to produce foods such as ready-to-eat cereal, pasta, candy, croutons, flour, and pet food. There are several types of extruders for food production, including single-screw and twin-screw. However, they all usually serve the same purpose: to produce various foods from certain starting materials and under specific extrusion conditions. Extrusion is most often used to cook, texturize, expand, and shape the desired food. During this process, raw ingredients are inserted into the extruder, customarily through a feed bin. The main screw inside the extruder is operated by the power supply and mixes the substance while it is being heated. As this happens the product is moving toward the die, where it exits the machine. Upon leaving the machine, the product usually increases in size due to the release of steam.

Numerous studies have shown that extrusion can have a definite positive nutritional effect on food, if it is done appropriately. According to Singh et al. (2007), these advantageous results include the destruction of anti-nutritional factors, increased soluble dietary fiber, reduction of lipid oxidation, and the gelatinization of starch. There are, however, very specific extrusion conditions necessary to produce a product that possesses these properties. These conditions vary depending on what is being extruded, but there appear to be some common necessary elements among the different foods. It has been shown in previous research, for example, that if the extrusion temperature is too high, burning and jamming of the machine results, as well as protein denaturation. On the other hand, if temperature is too low, the necessary extruded products may not form. Moisture content plays a very significant role in the process. If the moisture content is too high the extruder will become jammed. However, if there is not enough moisture in the mix, the product will not stay bound because the starch cannot gelatinize. The studies that Singh conducted showed that the best overarching extrusion conditions for high nutritional quality were high moisture content, low residence time, and low temperatures.

While the market for extruded cereals and snacks is quite large, it seems to be shrinking everyday, as more people transition to gluten-free diets. A gluten-free lifestyle is an increasingly popular dietary option that urges 
people to give up all products containing gluten in their diets. A large portion of society is choosing this dietary option for a variety of health reasons such as the progressively common Celiac disease. While gluten is also one of the most common food intolerances, many people also choose to participate in diets for non-medical reasons. For all of these reasons, the gluten-free market is rapidly growing. If we were able to utilize the technology of extrusion to produce gluten-free snacks, this would greatly expand the market for extruded products. The production of gluten-free snacks by way of extrusion would be a huge step forward for the snack industry.

The grains that are commonly used to take advantage of the nutritional benefits of extrusion are corn and rice. There is, however, the possibility of producing healthy foods from less common grains such as quinoa, and amaranth. Both of these grains are gluten-free, but very little research has investigated extrusion of each of these grains.. The growing gluten-free market provides a huge potential opportunity for extruded gluten-free products.

Quinoa is one of the grains that falls into the gluten-free category. The largest producers of this grain are Bolivia and Peru with $88 \%$ of the world's quinoa. The next largest producer is the United States with only a fraction of its production, $6 \%$. This is an ideal seed to grow because it is drought and frost resistant, grows in poor soil, and grows at high altitudes. Like chia, quinoa is ideal for use in the extrusion of snack foods because of its health benefits. According to Vilche et al. (2003), these seeds contain $10 \%$ to $18 \%$ protein, $4.5 \%$ to $8.75 \%$ crude fat, $54.1 \%$ to $64.2 \%$ carbohydrates, $2.4 \%$ to $3.64 \%$ crude fiber, and a first limiting amino acid of lysine, which is readily available in these seeds. This alone shows quinoa to be nutritionally superior to wheat. Another study, by Ahamed et al. (1998), had very similar results to these for the chemical composition of quinoa - typical compositions are shown in Table 1. The high protein content of quinoa makes it a great alternative to flour for gluten-free goods. Also, the fact that it is low in fat makes quinoa a promising grain to end up with a cohesive extrudate. Dogan and Karwe (2003) discuss the properties of this grain after extrusion. It was found that the protein is rich in lysine, methionine, and cysteine. This extrudate also has more than double the protein of corn and rice. For all of these reasons, quinoa is an ideal grain to extrude for the purpose of producing gluten-free snacks.

Table 1. Typical chemical properties of quinoa and amaranth seeds. All nutrients reported on a dry basis. Based upon Ahamed et al. (1998), and Vilche et al. (2003).

\begin{tabular}{|c|c|c|c|c|c|c|}
\hline Grain & Moisture & Ash & Protein & Fat & Carbohydrate & Crude Fiber \\
\hline Quinoa & $10-13 \%$ & $3 \%$ & $12-19 \%$ & $5-10 \%$ & $61-74 \%$ & $2-3 \%$ \\
\hline Amaranth & $6-9 \%$ & $3-4 \%$ & $13-18 \%$ & $6-8 \%$ & $63 \%$ & $4-14 \%$ \\
\hline
\end{tabular}

Amaranth is yet another gluten-free grain. It is most common in Peru, Bolivia, and Mexico. Its yields change significantly depending on the growing season, location, and soil moisture. Amaranth is an ideal grain to use in the extrusion of gluten-free snack foods. It has definite health benefits as well. Abalone et al. (2004) indicated that these seeds have $16 \%$ to $18 \%$ protein, and high lysine and tryptophan content. Ahamed et al. (1998) showed amaranth to have $13-18 \%$ protein, $6-8 \%$ fat, $63 \%$ carbohydrates, and $4-14 \%$ crude fiber. Similar to quinoa, amaranth has high protein content, making it ideal to use in gluten-free goods. The low fat content of amaranth makes it an ideal grain to extrude without jamming the machine. Another study, conducted by Ilo et al. (1999), discussed the extrusion of amaranth. The study found that extruding this grain helped to increase the availability of protein and nutrients. Due to the positive nutritional qualities of amaranth and the fact that it is gluten-free, it is an ideal grain to extrude into gluten-free snack foods.

Both of the grains (amaranth and quinoa) have nutritional qualities of value to the human body. Several studies have shown that extruding these grains has further increased their nutritional value. Thus the purpose of this project was to utilize the grains quinoa and amaranth to produce gluten-free snacks.

\section{Materials and Methods}

\subsection{Raw Ingredients}

White quinoa seeds were obtained from Roland. Amaranth was obtained from Angelina's Gourmet. Two kilograms of each of the raw ingredients were ground using a Wiley laboratory mill (model 4, Thomas Scientific, Swedesboro, NJ) to an average particle size of $2 \mathrm{~mm}$, two kilograms were ground using a $1 \mathrm{~mm}$ screen, and two kilograms were left raw. Moisture content of each was determined using a drying oven at $135^{\circ} \mathrm{C}$ for two hours. Enough water was added to one kilogram of each sample to achieve $20 \% \mathrm{db}$ moisture and to the other kilogram to reach $40 \% \mathrm{db}$ moisture. The products were divided into the following categories: raw grain at $20 \%$ and $40 \%$ moisture content, $1 \mathrm{~mm}$ particle size at $20 \%$ and $40 \%$ moisture content, and $2 \mathrm{~mm}$ particle size at $20 \%$ and $40 \%$ 
moisture content.

\subsection{Extrusion Processing}

The extrusion of each of the blends was carried out using a single-screw extruder (model PL 2000 Plasti-Corder, Brabender South Hackensack, NJ) with a screw compression ratio of 1:1, a screw length-to-diameter ratio of 20:1, and a barrel length of $317.5 \mathrm{~mm}$ (Figure 1). The die had a diameter of $3.0 \mathrm{~mm}$. Each blend was extruded at screw speeds of $50 \mathrm{rpm}$ and $100 \mathrm{rpm}$. The raw blends were manually scooped into the barrel of the extruder and forced through with a wooden rod to ensure no jamming would take place. Temperatures were monitored at the feed, transition, and die zones.

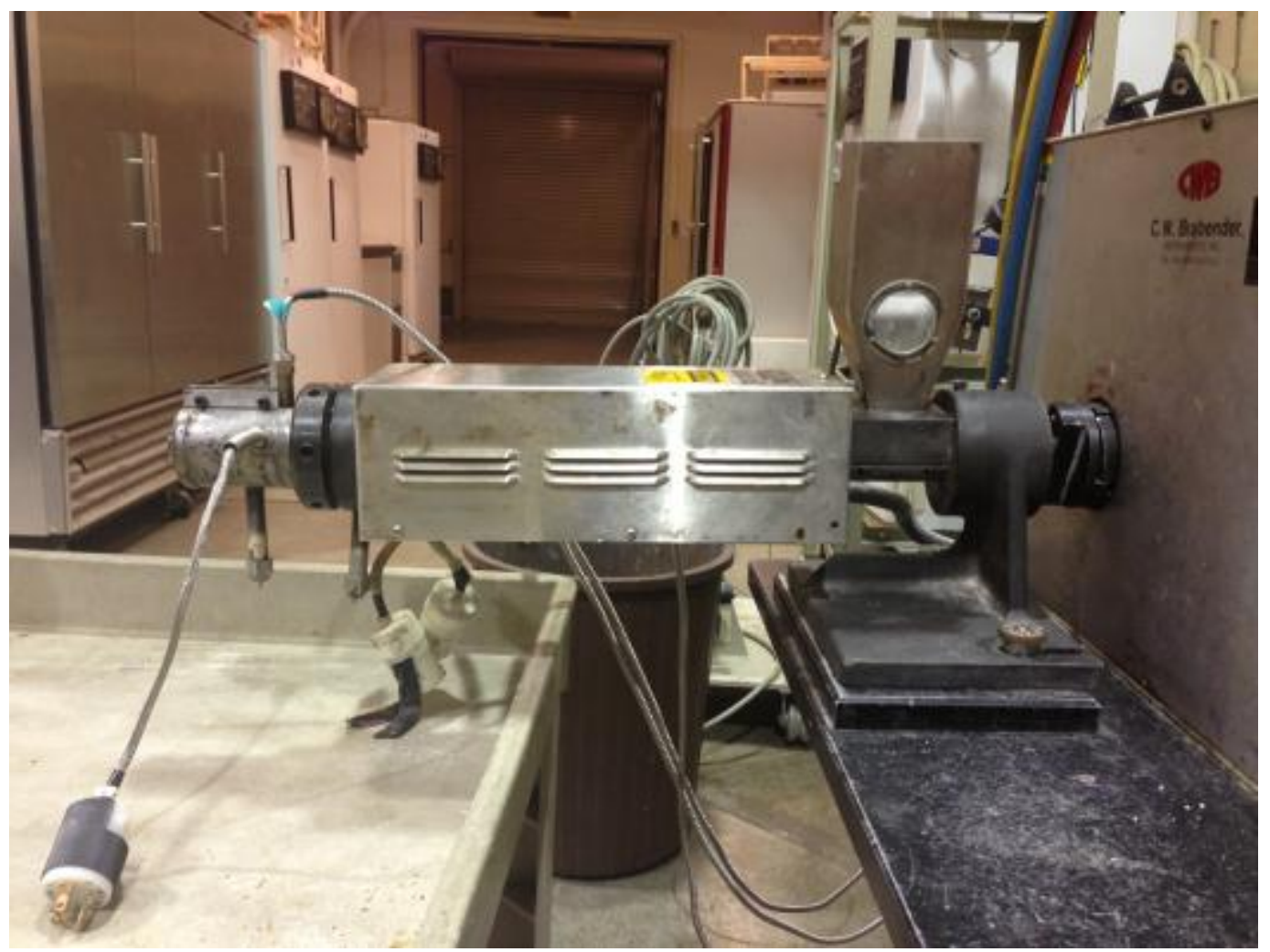

Figure 1. Brabender single-screw extruder used to extrude blends. Conditions included a $3 \mathrm{~mm}$ die and a screw compression ratio of $1: 1$

\subsection{Raw Ingredient Properties}

After the ingredients were mixed to their necessary moisture contents, the blends were analyzed in terms of color. To determine the color of the mixtures, a spectrometer (LabScan XE, HunterLab, Reston, VA) was used. The L* value measured the lightness/darkness, the $a^{*}$ value quantified the redness/greenness, and the $b^{*}$ value signified the yellowness/blueness. The moisture content of the raw ingredient mixes were also tested for moisture content after extrusion to ensure the values matched the expected moisture contents.

\subsection{Extrudate Properties}

After extrusion, the products were dried in a laboratory oven at $50^{\circ} \mathrm{C}$ for 24 hours. The extrudates were then analyzed for color, unit density $\left(\mathrm{kg} / \mathrm{cm}^{3}\right)$, expansion ratio, and pellet durability index $(\%)$. The extrudate color was measured using the same process as the raw ingredient color was measured. A spectrometer (LabScan XE, HunterLab, Reston, VA) was used to determine the $L^{*}$ value (measuring lightness/darkness), the $a^{*}$ value (measuring redness/greenness), and the $\mathrm{b}^{*}$ value (measuring yellowness/blueness). To measure unit density, each extrudate was cut to sections of length $20 \mathrm{~mm}$. They were then weighed on a balance and measured with a caliper to conclude their diameters. The unit density was determined by dividing the mass $(\mathrm{kg})$ by the volume $\left(\mathrm{cm}^{3}\right)$ because of the extrudates' cylindrical shape. To calculate the expansion ratio, the actual diameter of the extrudates $(\mathrm{mm})$ was divided by the diameter of the die $(3 \mathrm{~mm})$. To measure pellet durability index, $100 \mathrm{~g}$ of each extrudate was tumbled in a pellet durability tester (model PDT-110, Seedburo Equipment, Chicago, IL) for $10 \mathrm{~min}$. Then, products were sieved for $15 \mathrm{sec}$, and again weighed on an electronic balance. The final weight was 
divided by the initial weight $(100 \mathrm{~g})$ and multiplied by 100 , resulting in a percentage. The results of these analyses are shown in Table 5 and Table 6 for quinoa and amaranth, respectively. Figure 2 and Figure 3 show the blends before and after extrusion for comparison.
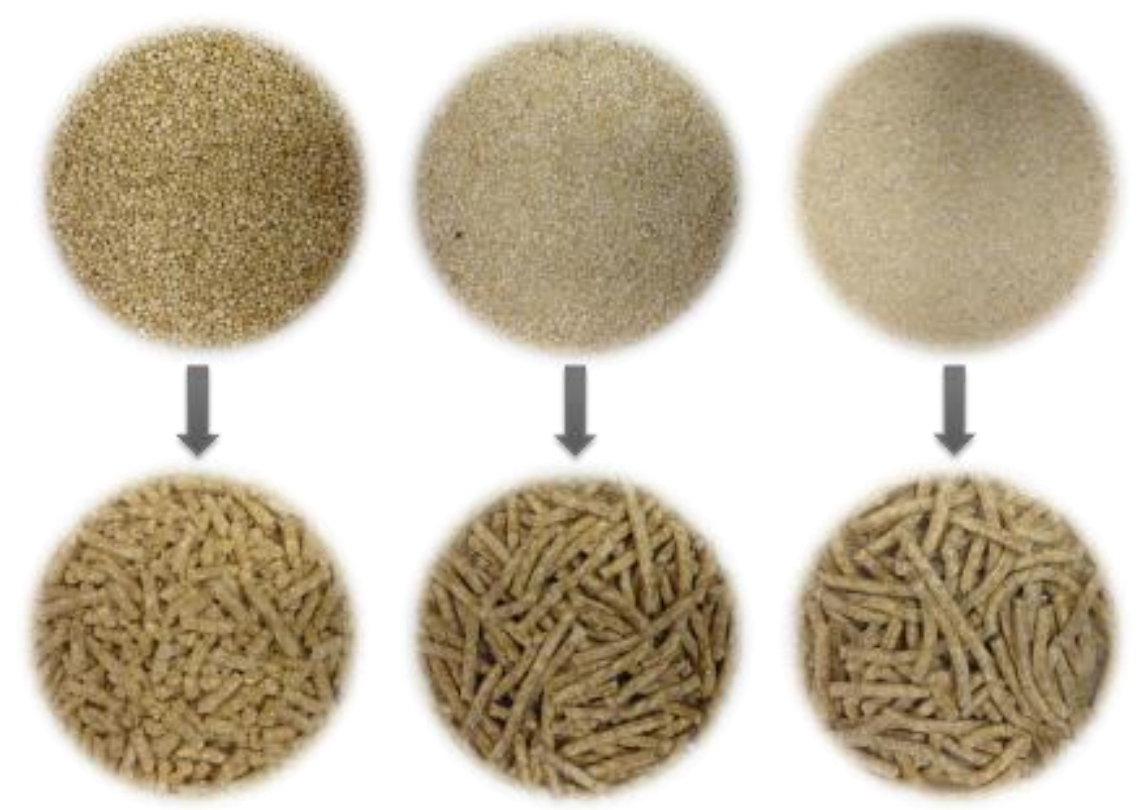

Figure 2. Raw quinoa (above) and extrudates (below) for treatments 2, 6, and 10, respectively (see Table 2 for treatments)
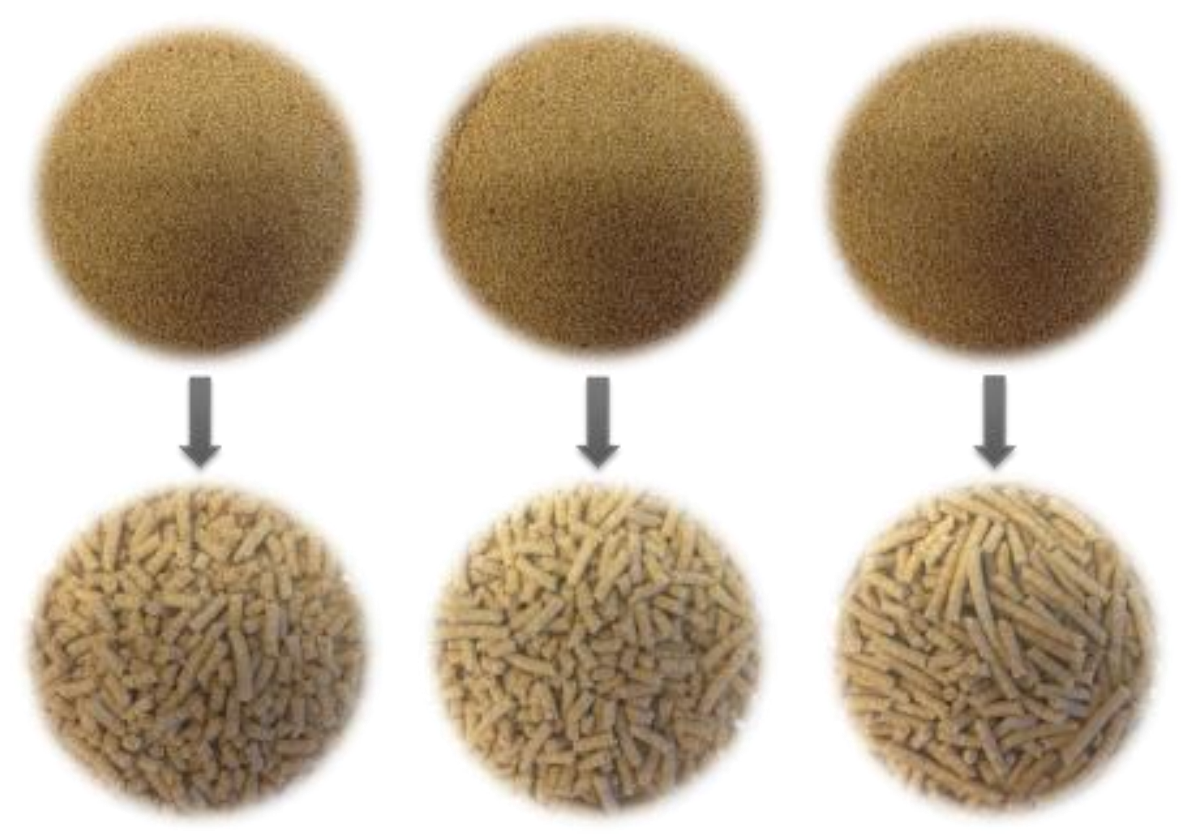

Figure 3. Raw amaranth (above) and extrudates (below) for treatments 2, 6, and 10, respectively (see Table 2 for treatments)

\subsection{Experimental Design}

The experimental design was based on a $3 \times 2 \times 2$ matrix with varying dependent variables of particle size, moisture content, and screw speed, respectively (as shown in Table 2). Particle size was divided into 3 groups of raw grain, $2 \mathrm{~mm}$ average particle size, and $1 \mathrm{~mm}$ average particle size. Moisture content was split into 2 categories of $20 \% \mathrm{db}$ and $40 \% \mathrm{db}$. All 6 blends were extruded at screw speeds $50 \mathrm{rpm}$ and $100 \mathrm{rpm}$, resulting in 12 different treatment options. Each treatment was replicated (i.e., extruded) twice. 
Table 2. Experimental design including treatment numbers and independent variables

\begin{tabular}{|c|c|c|c|}
\hline Treatment & Particle Size & Moisture Content (\% db) & Screw Speed (rpm) \\
\hline 1 & Raw & 20 & 50 \\
2 & & 20 & 100 \\
3 & & 40 & 50 \\
\hline 4 & & 40 & 100 \\
5 & $2 \mathrm{~mm}$ & 20 & 50 \\
\hline 6 & & 20 & 100 \\
7 & & 40 & 50 \\
\hline 8 & & 40 & 100 \\
9 & $1 \mathrm{~mm}$ & 20 & 50 \\
10 & & 20 & 100 \\
11 & & 40 & 50 \\
12 & & 40 & 100 \\
\hline
\end{tabular}

\subsection{Data Analysis}

For each extrudate, all physical properties were measured 3 separate times except durability where one measurement was taken. All measurements were used to calculate the average and standard deviation of each property. Measured properties included both measurements from raw grain (moisture content, and $\mathrm{L}^{*}, \mathrm{a}^{*}$, and $\mathrm{b}^{*}$ color) and the extrudates ( $\mathrm{L}^{*}, \mathrm{a}^{*}, \mathrm{~b}^{*}$, unit density, expansion ratio, and pellet durability).

\section{Results and Discussion}

\subsection{Raw Ingredient Properties}

Moisture Content: Not only is moisture content of the extrudates important, but moisture content of the raw grains is as well. This is a large indicator as to how easily the blend will extrude. If moisture content is too low, the final product will not stay bound. However, if the moisture content of the blend is too high, the blend will jam the extruder and not produce a product. Table 5 and Table 6 show, in column 3, the actual moisture content of blends for quinoa and amaranth, respectively. The average moisture content of the $20 \% \mathrm{db}$ quinoa was $23.67 \%$ $\mathrm{db}$, and the average moisture content for the $40 \% \mathrm{db}$ quinoa was $41.11 \% \mathrm{db}$. For amaranth, the average moisture content of the $20 \% \mathrm{db}$ grain was $24.29 \% \mathrm{db}$, and the average moisture content for the $40 \%$ grain was $42.17 \% \mathrm{db}$. The variance was low for the moisture content of both grains and the mixtures were utilized for the extrusion.

Color: Color was measured for each blend before extrusion and the quinoa results are also presented in Table 5 . For quinoa, the $\mathrm{L}^{*}$ value decreased for each grain size as moisture content increased from 20 to $40 \%$. There was no correlation between moisture content and particle size and either $\mathrm{a}^{*}$ or $\mathrm{b}^{*}$. The amaranth data is shown in Table 6. Neither moisture content or particle size have an impact on the $\mathrm{L}^{*}$ value. However, $\mathrm{a}^{*}$ decreases as grain size decreases. $\mathrm{B}^{*}$ decreases as both moisture content and particle size decrease.

\subsection{Extrudate Properties}

Extrusion conditions were monitored and temperatures were measured during processing (Tables 3 and 4). Extrudate properties are shown in Tables 5 and 6.

Table 3. Temperatures measured at the die, transition, and feed zones for the extrusion of quinoa

\begin{tabular}{|c|c|c|c|}
\hline & \multicolumn{3}{|c|}{${\text { Temperature }\left({ }^{\circ} \mathrm{C}\right)}$} \\
Treatment & Die & Transition & Feed \\
\hline 1 & 54 & 50 & 29 \\
2 & 45 & 50 & 36 \\
3 & 54 & 42 & 30 \\
4 & 55 & 69 & 33 \\
5 & 60 & 59 & 32 \\
6 & 54 & 64 & 36 \\
7 & 59 & 58 & 34 \\
8 & 58 & 72 & 42 \\
9 & 38 & 59 & 31 \\
10 & 61 & 76 & 46 \\
11 & 28 & 34 & 23 \\
12 & 61 & 71 & 44 \\
\hline
\end{tabular}


Table 4. Temperatures measured at the die, transition, and feed zones for the extrusion of amaranth

\begin{tabular}{|c|c|c|c|}
\hline & \multicolumn{3}{|c|}{ Temperature ("C) } \\
Treatment & Die & Transition & Feed \\
\hline 1 & 30 & 39 & 25 \\
\hline 2 & 25 & 25 & 25 \\
3 & 43 & 52 & 27 \\
\hline 4 & 38 & 51 & 27 \\
5 & 52 & 53 & 29 \\
6 & 50 & 53 & 29 \\
\hline 7 & 56 & 53 & 30 \\
\hline 8 & 54 & 54 & 30 \\
\hline 9 & 57 & 47 & 31 \\
\hline 10 & 57 & 48 & 30 \\
\hline 11 & 57 & 45 & 30 \\
12 & 56 & 47 & 30 \\
\hline
\end{tabular}

Table 5. Mean properties of quinoa extrudates (standard deviation in parentheses)

\begin{tabular}{|c|c|c|c|c|c|c|c|c|c|c|c|}
\hline \multirow{3}{*}{ Treatment } & \multirow[b]{3}{*}{ Trial } & \multicolumn{4}{|l|}{ Raw Properties } & \multicolumn{6}{|c|}{ Extrudate Properties } \\
\hline & & \multirow{2}{*}{$\begin{array}{c}\text { Moisture Content } \\
(\mathrm{db}, \%)\end{array}$} & & \multicolumn{3}{|c|}{ Color } & \multirow{2}{*}{$\begin{array}{l}\text { Unit Density } \\
\left(\mathrm{g} / \mathrm{cm}^{\wedge} 3\right)\end{array}$} & \multirow{2}{*}{$\begin{array}{c}\text { Expansion } \\
\text { Ratio }\end{array}$} & \multirow{2}{*}{$\begin{array}{l}\text { Pelet Durabiilty } \\
\text { Index (\%) }\end{array}$} \\
\hline & & & $t^{*}$ & $a^{*}$ & $b^{*}$ & $L^{*}$ & $a^{*}$ & $b^{*}$ & & & \\
\hline \multirow[t]{2}{*}{1} & Average & 21.87 & 76.16 & 3.79 & 25.99 & 65.31 & 4.83 & 26.14 & \begin{tabular}{|l|}
1.16 \\
\end{tabular} & 1.12 & 81.9 \\
\hline & Standard Deviation & (0.32) & (0.14) & $(0.02)$ & (0.18) & $(0.03)$ & $(0,01)$ & {$[0.01]$} & $(0.05)$ & $(0.02)$ & - \\
\hline \multirow[t]{2}{*}{2} & Average & 21.87 & 76.16 & 3.79 & 25.99 & 64.81 & 4.55 & 26.94 & 1.14 & 1.09 & 68.6 \\
\hline & Srandard Deviation & $(0.32)$ & $(0.14)$ & $(0.02)$ & (0.18) & (1.14) & $(0.15)$ & (0.38) & $(0.04)$ & $(0.02)$ & - \\
\hline \multirow[t]{2}{*}{3} & Average & 39.84 & 75.41 & 3.6 & 24.28 & 57.78 & 6.55 & 24.23 & 1.1 & 1.06 & 92 \\
\hline & Standard Deviation & $(0.79)$ & $(0.02)$ & $(0.02)$ & $(0.01)$ & $(0.12)$ & $(0.02)$ & $(0.01)$ & $(0.03)$ & $(0.01)$ & - \\
\hline \multirow[t]{2}{*}{4} & Average & 39.84 & 75.41 & 3.6 & 24.28 & 69.14 & 5.35 & 27.81 & 1.51 & 0.92 & 95.8 \\
\hline & Standard Devation & $(0.79)$ & (0.02) & {$[0.02]$} & (0.01) & (0.23) & $(0.21)$ & {$[0.26]$} & $(0.45)$ & (0.12) & . \\
\hline \multirow[t]{2}{*}{5} & Average & 25.42 & 84.65 & 229 & 19.47 & 61.59 & 4.1 & 21.8 & 1.15 & 1.13 & 97.1 \\
\hline & Standard Deviatian & (0.33) & (0.02) & {$[0.01]$} & (0.01) & $(0.03)$ & (0.03) & {$[0.02]$} & $(0.09)$ & (0.01) & - \\
\hline \multirow[t]{2}{*}{6} & Average & 25.42 & 84.65 & 229 & 19.47 & 58.07 & 3.7 & 20.98 & 1.21 & 1.09 & 96.4 \\
\hline & Standard Deviation & (0.33) & $(0.02)$ & {$[0.01]$} & (0.01) & (0.14] & $\{0.01\rangle$ & {$[0.06]$} & $(0.02)$ & $\langle 0.01\rangle$ & - \\
\hline \multirow[t]{2}{*}{7} & Average & 44.45 & 83.36 & 233 & 18.57 & 67.53 & 4.8 & 20.3 & 1.25 & 1.03 & 98.4 \\
\hline & Standard Deviation & $(1.30)$ & (0.04) & {$[0.01]$} & (0.01) & (0.24) & $(0.02)$ & {$[0.04]$} & $(0.04)$ & $(0.01)$ & - \\
\hline \multirow[t]{2}{*}{8} & Average & 44.45 & 83.36 & 233 & 18.57 & 56.85 & 4.71 & 21.53 & 1.17 & 1.07 & 96 \\
\hline & Standard Deviation & $(1.30)$ & $(0.04)$ & {$[0.01]$} & $(0.01)$ & $(0.09)$ & $(0.02)$ & {$[0.03]$} & $\{0.05\}$ & $(0.04)$ & - \\
\hline \multirow[t]{2}{*}{9} & Average & 23.72 & 85.62 & 185 & 18.6 & 60.01 & 3.22 & 18.44 & 1.25 & 1.1 & 88.2 \\
\hline & Standard Deviation & $(0.69)$ & $(0.07)$ & $(0.05)$ & (0.16) & $(0.32)$ & $(0.03)$ & $(0.01)$ & $(0.07)$ & $(0.03)$ & - \\
\hline \multirow[t]{2}{*}{10} & Average & 23.72 & 85.62 & 185 & 18.6 & 58.09 & 3.86 & 21 & 1.17 & 1.13 & 98.5 \\
\hline & Standard Devlation & (0.69) & $\langle 0.07\rangle$ & $(0.05)$ & (0.16) & $(0.67)$ & $\langle 0.03\rangle$ & {$[0.17)$} & $\langle 0.08\rangle$ & $(0.05)$ & 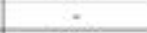 \\
\hline \multirow[t]{2}{*}{11} & Average & 39.04 & 81.71 & 24 & 19.91 & 67.35 & 4.17 & 19.76 & 1.21 & 0.99 & 99.6 \\
\hline & Standard Deviation & $\langle 0.47\rangle$ & $(0.02)$ & {$[0.01]$} & (D.01) & (0.64) & (0.03) & {$[0.17)$} & $\langle 0.10\rangle$ & $(0.02\rangle$ & - \\
\hline \multirow[t]{2}{*}{12} & Average & 39.04 & 81.71 & 24 & 19.91 & 56.4 & 5.22 & 24.1 & 1.29 & 1.04 & 96 \\
\hline & Standard Deviation & $(0.47)$ & $(0.02)$ & {$[0.01]$} & (0.01) & $(0.46]$ & $(0.04)$ & {$[0.32]$} & $\{0.04\}$ & (0.01) & - \\
\hline
\end{tabular}

Table 6. Mean properties of amaranth extrudates (standard deviation in parentheses)

\begin{tabular}{|c|c|c|c|c|c|c|c|c|c|c|c|}
\hline \multirow[b]{3}{*}{ Treatment } & \multirow[b]{3}{*}{ Trial } & \multirow{3}{*}{$\begin{array}{l}\text { Raw Properties } \\
\text { Maisture Content } \\
\text { [db, } \% \text { ] }\end{array}$} & \multirow{2}{*}{\multicolumn{3}{|c|}{ Color }} & \multicolumn{6}{|c|}{ Extrudate Properties } \\
\hline & & & & & & & Color & & Unit Density & Expansion & Pellet Durability \\
\hline & & & L* & $a^{*}$ & $b^{*}$ & $L^{*}$ & $a^{*}$ & $b^{*}$ & {$\left[\mathrm{~g} / \mathrm{cm}^{N} 3\right]$} & Ratio & Index (\$) \\
\hline \multirow[t]{2}{*}{1} & Average & 24.5 & 63.33 & 7.24 & 29.09 & 59.99 & 9.01 & 27.25 & 1.11 & 1.07 & 80 \\
\hline & Standard Deviation & $\{0.29\}$ & $(0.06)$ & $(0.01)$ & $(0.01)$ & {$[0.01)$} & $(0.03)$ & $(0.01)$ & $(0.06)$ & (0.03) & - \\
\hline \multirow[t]{2}{*}{2} & \begin{tabular}{|c|} 
Average \\
\end{tabular} & 24.5 & 63.33 & 7.24 & 29.09 & 66.33 & 7.24 & 29.09 & 0.9 & 1.18 & 82.5 \\
\hline & Standard Deviation & {$[0.29]$} & $(0.06)$ & $(0.01)$ & $(0.01)$ & $(0.06)$ & (0.01) & (0.01) & $(0.08)$ & $(0.03)$ & 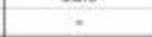 \\
\hline \multirow[t]{2}{*}{3} & Average & 41.61 & 63.52 & 8.4 & 28.62 & 53.18 & 9.64 & 26.13 & 1.43 & 1.04 & 95.9 \\
\hline & Standard Deviation & (1.63) & $(0.03)$ & $(0.01)$ & $(0.01)$ & $(0.02)$ & $(0.01)$ & $(0.03)$ & $(0.36)$ & $(0.01)$ & $\cdot$ \\
\hline \multirow[t]{2}{*}{4} & Average & 41.61 & 63.52 & 8.4 & 28.62 & 63.52 & 8.4 & 28.62 & 1.25 & 1.07 & 93.6 \\
\hline & Standard Deviation & $\{1.63\}$ & (0.03) & $(0.01)$ & $(0.01)$ & $(0.03)$ & $\{0.01\}$ & (0.01) & $(0.05)$ & $(0.02)$ & - \\
\hline \multirow[t]{2}{*}{5} & Average & 24.19 & 25.3 & 7.08 & 28.43 & 56.41 & 8.42 & 25.38 & 1.08 & 1.16 & 95.3 \\
\hline & Standard Deviation & $(0.23)$ & $(0.06)$ & $(0.04)$ & $(0.06)$ & $(0.02)$ & $(0.02)$ & $(0.02)$ & $(0.02)$ & $\langle 0.01\rangle$ & + \\
\hline \multirow[t]{2}{*}{6} & Average & 24.19 & 25.3 & 7.08 & 28.43 & 65.2 & 7.08 & 28.43 & 1.11 & 1.15 & 94.4 \\
\hline & Standard Deviation & {$[0.23)$} & $(0.06)$ & $(0.04)$ & $(0.06)$ & {$[0.06)$} & {$[0.04]$} & $(0.06)$ & $(0.04)$ & $(0.02)$ & $\cdot$ \\
\hline \multirow[t]{2}{*}{7} & Average & 43.19 & 65.68 & 6.78 & 26.4 & 49.75 & 8.53 & 23.33 & 1.14 & 1.03 & 98.3 \\
\hline & Standard Deviation & $\{0.68\}$ & $(0.03)$ & $(0.01)$ & $(0.03)$ & $(0.03)$ & (D.01) & $(0.06)$ & $(0.02)$ & $(0.01)$ & 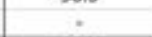 \\
\hline \multirow[t]{2}{*}{8} & Average & 43.19 & 65.68 & 6.78 & 26.4 & 65.68 & 6.78 & 26.4 & 1.16 & 1.03 & 98.4 \\
\hline & Standard Deviation & (0.68) & $(0.03)$ & $(0.01)$ & $(0.03)$ & {$[0.03)$} & [0.01] & $(0.03)$ & $(0.07)$ & $(0.03)$ & - \\
\hline \multirow[t]{2}{*}{9} & Average & 24.17 & 67.02 & 6.19 & 26.11 & 52.34 & 7.02 & 21.81 & 1.02 & 1.34 & 81.7 \\
\hline & Standard Deviation & {$[0,04)$} & $(0.04)$ & $(0.02)$ & $(0.09)$ & {$[0.02)$} & $(0.02)$ & $(0.02)$ & $(0.01)$ & $(0.01)$ & - \\
\hline \multirow[t]{2}{*}{10} & Average & 24.17 & 67.02 & 6.19 & 26.11 & 67.02 & 6.19 & 26.11 & 1.01 & 1.14 & 80.2 \\
\hline & Standard Deviation & $(0.04)$ & $(0.04)$ & $(0.02)$ & $(0.09)$ & $(0.04)$ & $(0.02)$ & $(0.09)$ & $(0.03)$ & $\langle 0.01\}$ & - \\
\hline \multirow[t]{2}{*}{11} & Average & 41.71 & 62.59 & 6.42 & 24.97 & 53.3 & 6.27 & 19.23 & 1.13 & 1.05 & 95.3 \\
\hline & Standard Deviation & $(0.84)$ & $\langle 0.05\rangle$ & $(0.01)$ & $(0.03)$ & $(0.03)$ & $(0.03)$ & $(0.01)$ & $(0.03)$ & $\langle 0.01\rangle$ & - \\
\hline \multirow[t]{2}{*}{12} & Average & 41.71 & 62.59 & 6.42 & 24.97 & 62.59 & 6.42 & 24.97 & 1.18 & 1.05 & 96.2 \\
\hline & Standard Deviation & $\{0.84\}$ & $(0.05)$ & $(0.01)$ & $(0.03)$ & $(005)$ & (D.01) & (0.03) & $(0.05)$ & $(0.02)$ & $=$ \\
\hline
\end{tabular}


Table 5 displays the quinoa extrudate properties. It shows what effects moisture content, grain particle size, and extruder screw speed had on color $\left(\mathrm{L}^{*}, \mathrm{a}^{*}, \mathrm{~b}^{*}\right)$, unit density, expansion ratio, and pellet durability index. The values included in this table are the average of 3 trials and the standard deviation for each extrudate property. Table 6 shows the same extrudate properties for amaranth. It also provides the effects of the same control variables stated above on the properties of color $\left(\mathrm{L}^{*}, \mathrm{a}^{*}, \mathrm{~b}^{*}\right)$, unit density, expansion ratio, and pellet durability index.

Color: Extrudate color is very important when it comes to customer approval, especially when dealing with human foods. If the extrudate doesn't visually appeal to the consumers, it can be a problem. The three categories by which color is measured are $\mathrm{L}^{*}, \mathrm{a}^{*}$, and $\mathrm{b}^{*}$. According to the quinoa data in Table 5, Treatment 4 had the highest $L^{*}$ value of 69.14 and Treatment 12 had the lowest with a value of 56.4. As the screw speed increased, $\mathrm{L}^{*}$ decreased. The lowest $\mathrm{a}^{*}$ value of 3.22 came from Treatment 9 . The highest value of 6.55 came from Treatment 3, which was significantly higher than all of the other treatments. Data analysis showed that as the moisture content increased, the $\mathrm{a}^{*}$ value of the extrudates increased, but as the particle size decreased, the $\mathrm{a}^{*}$ values decreased. The lowest $b^{*}$ value came from Treatment 9 , and was measured to be 18.44 , which was considerably lower than the other values. The highest $b^{*}$ value of 27.81 was measured from Treatment 4 . Treatments 1,2,3, and 4, which were all blends made with raw grain, had higher $b^{*}$ values than the rest of the treatments. As the particle size decreased, $b^{*}$ values decreased. As the screw speed increased, the $b^{*}$ value increased as well. According to the amaranth data in Table 6, the lowest $\mathrm{L}^{*}$ value, from Treatment 8 , of 49.75 , was significantly lower than any other $\mathrm{L}^{*}$ value. The highest $\mathrm{L}^{*}$ value was 67.02 , from treatment 11 . As the screw speed increased, the $\mathrm{L}^{*}$ value increased as well. The lowest measured $\mathrm{a}^{*}$ value was from Treatment 10 and was measured as 6.19. Other low a* values were from Treatments 8,11 , and 12 . The highest value was 9.64, from Treatment 3. As the particle size decreased, there was a decrease in $\mathrm{a}^{*}$. Amaranth appeared to have higher $a^{*}$ values than quinoa did, meaning it was more red than green on the color scale. Significantly lower than the rest, Treatment' 11's b* value was 19.23. The highest value came from Treatment 2 at 29.09. Other treatments with high $b^{*}$ values were Treatments 4 and 6 . As the grain size decreased, $b^{*}$ decreased. However, as the screw speed increased, so did $b^{*}$. The more moisture a grain contains, the darker it tends to be. This means that the $\mathrm{L}^{*}$ value would be lower. Since amaranth had the lowest $\mathrm{L}^{*}$ value, it is likely less water evaporated from the amaranth blends than it did from the quinoa blends.

According to Taverna et al. (2012), in an extrusion of quinoa flour and industrial sour cassava blends, after extrusion, the blends' $L^{*}$ values varied from 53.05 to 74.69 , which are similar to the values found in Table 5. The same study also shows that the $\mathrm{L}^{*}$ value decreased after extrusion, which is consistent with Table 5 as well. The study with the blends of quinoa and industrial sour cassava had a* values ranging from 4.64 to 6.43 (Taverna, 2012). These $a^{*}$ values are also similar to those in Table 5. The amaranth and sour cassava blends had $b$ values from 10.88 to 20.86 (Taverna, 2012). These values for $b^{*}$ are significantly lower than those found in Table 5 .

Unit Density: Due to the need to control nutrients in extruded foods, unit density is an important property to measure. Table 5 shows that Treatment 3 had the lowest unit density of quinoa, with a value of $1.1 \mathrm{~g} / \mathrm{cm}^{3}$. Treatments 1, 2, 5, 8, and 10 also had very low unit density values. The highest value of mass per unit density came from Treatment 4 , which was significantly higher than any of the other treatments. Treatment 4 had a unit density of $1.51 \mathrm{~g} / \mathrm{cm}^{3}$. There was no correlation between unit density and moisture content, particle size, or screw speed. According to Table 6, the amaranth blend with the lowest unit density was Treatment 2 , with a value of $0.9 \mathrm{~g} / \mathrm{cm}^{3}$. This is considerably lower than any other treatments. Treatment 3 had the highest unit density with a value of $1.43 \mathrm{~g} / \mathrm{cm}^{3}$. Treatments 3 and 4 had substantially larger unit density values than the rest of the treatments. As the moisture content in the amaranth blends increased, the extrudates' unit density increased. The two grains likely had similar unit densities because they were both tested at the same moisture content levels. Our results show that amaranth had significantly lower values for unit density than did quinoa. According to Table 1, quinoa is much higher in the percentages of carbohydrates than amaranth, so this may explain the higher unit density.

Expansion Ratio: The expansion ratio is the amount that the product puffs upon exiting the extruder and is a very important property when it comes to extrusion of human snack foods. According to Table 5, Treatments 4 and 11 were the quinoa blends with the lowest expansion ratios of 0.92 and 0.99 , respectively. These were the only two treatments with expansion ratios below 1, meaning they shrunk in size upon exiting the extruder. The largest value of expansion ratio came from Treatments 5 and 10, both with values of 1.13. As moisture content of the blends increased, there was a decrease in the expansion ratio of the extrudates. According to Table 6, the amaranth blend with the lowest unit density was Treatment 2 , with a value of 0.9 . This was the only treatment with an expansion ratio less than 1 . Treatment 9 had the highest value of 1.34 , which was considerably larger 
than the other treatments. As the blends' moisture content increased, the extrudates' expansion ratio decreased. Both grains had similar expansion ratios. This may be due to the fact that they were both extruded at the same moisture contents, which usually has the biggest affect on expansion. However, protein content may have large effects on expansion ratio as well. This is also consistent with the results in Tables 3,5, and 6. According to Table 1, the protein content in both quinoa and amaranth are between 12 and 19\%. Tables 3 and 5 show that the expansion ratios in both grains were very similar. Quinoa had an average expansion ratio of 1.06, and amaranth of 1.1. The blends' similar moisture and protein contents likely led to the comparable expansion ratios.

Pellet Durability Index: Pellet durability index (PDI) measures the breakage the extrudate is able to endure, and has great importance in the storage of foods. The higher the percentage, the stronger and less likely the product is to break. According to Table 5, the quinoa blend with the lowest pellet durability index was Treatment 2, with a PDI value of $68.6 \%$, which was significantly lower than the other treatments. Treatments 1 and 9 were similar in PDI values at 81.9 and $88.2 \%$, respectively. The highest pellet durability index value came from Treatment 11 , with 99.6\%. Other high PDI values were from Treatments 5, 7, and 10 with values of 97.1, 98.4, and 98.5\%, respectively. According to Table 6 , the amaranth blends with the lowest pellet durability index were Treatments 1 and 9 with values of 80 and $80.2 \%$, respectively. The treatments with the highest PDIs were Treatments 7 and 8 at 98.3 and $98.4 \%$, respectively. Protein content usually has an effect on durability of extrudates. However, it is likely that a quinoa treatment had the lowest PDI because, according to Table 1, it may contain more fat than amaranth. The more fat the grain contains, the less cohesive the extrudates tend to be.

Multivariate Relationships: Figure 4 (quinoa) and Figure 5 (amaranth) plot all extrudate dependent variables against each other in order to reveal potential relationships amongst the extrudate properties. It appears that there was some clustering due to moisture contents of the raw ingredients. For example, for quinoa, it seems that Hunter a and b, expansion ratio and PDI, and unit density and expansion ratio exhibited some clustering. For amaranth, it appears that most of the dependent variable relationships were clustered according to moisture. Although only two moisture contents were examined, it is likely that had additional moisture contents be tested, gaps in the data would have been filled and the full effect of moisture would have been determined. Furthermore, it appears that there may have been potential linear relationships between various dependent variables (although a formal correlation analysis was not completed). For example, for quinoa extrudates is appears that Hunter a and $b$, and also unit density and expansion ration may have a potential linear relationship. Additionally, for amaranth, it appears that linear relationships may occur between Hunter $\mathrm{L}^{*}$ and $a$, Hunter $\mathrm{L}^{*}$ and $b$, unit density and PDI, and also PDI and die temperature. The multivariate nature of these data may be worth further exploration in future studies, as this information could be useful for commercial scale-up and operation.

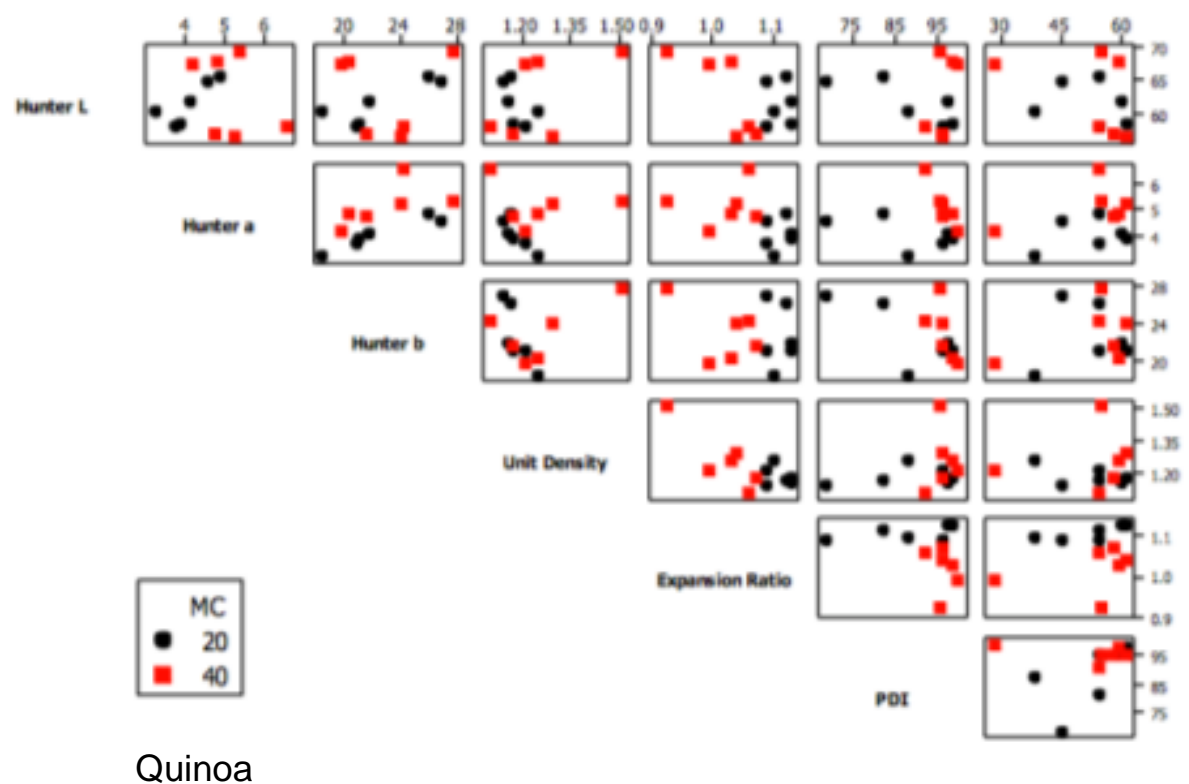

Figure 4. Relationships among all dependent variables for quinoa extrusion. Some clustering was evident due to the different moisture contents. A few linear trends were apparent as well. All units are the same as in Table 5 


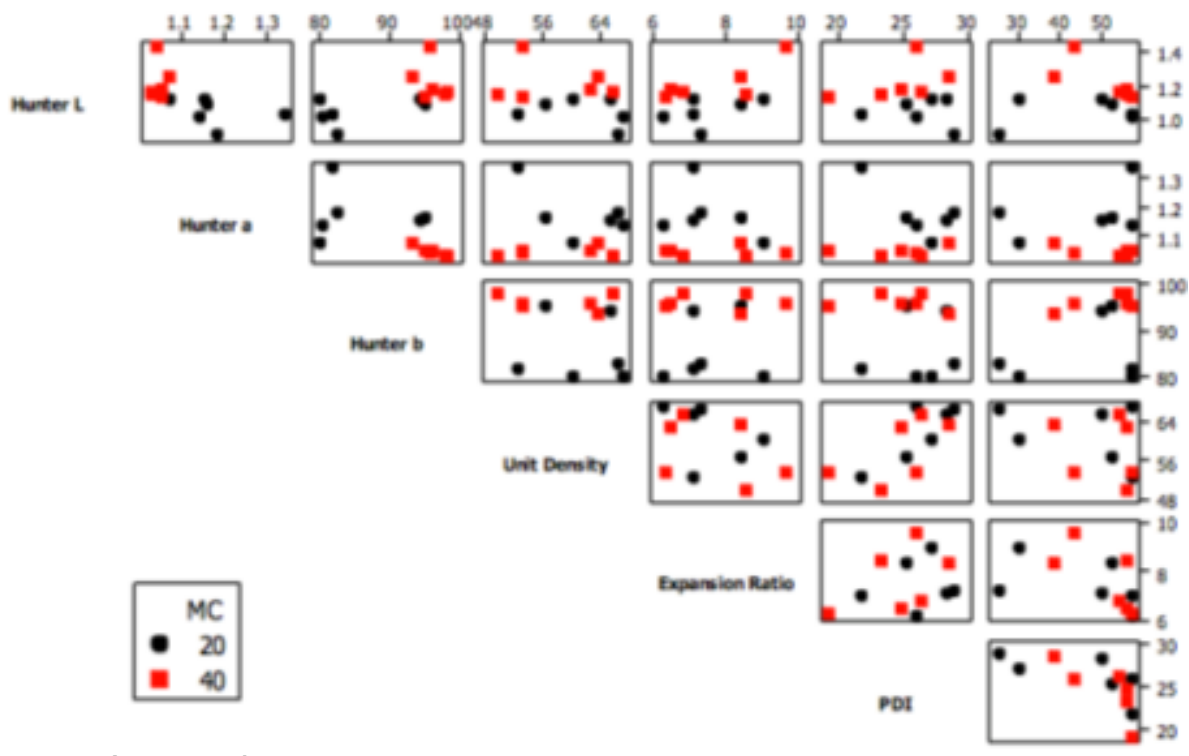

Amaranth

Figure 5. Relationships among all dependent variables from amaranth extrusion. Some clustering was evident due to the different moisture contents. A few linear trends were apparent as well. All units are the same as in

Table 6

\section{Conclusons}

It is possible to produce extruded products from the pure grains of quinoa and amaranth, mixed with only water. These grains can both be extruded at particle sizes of raw grain, $2 \mathrm{~mm}$, and $1 \mathrm{~mm}$, and at moisture contents of $20 \%$ $\mathrm{db}$ and $40 \% \mathrm{db}$. All extrusion was carried out on a single screw extruder with screw speeds of $50 \mathrm{rpm}$ and 100 rpm. Temperature was not regulated throughout the process, but varied according to frictional resistance during processing. As the moisture content increased, the $\mathrm{a}^{*}$ value of the extrudates increased, and there was a decrease in the extrudates' expansion ratio. As the quinoa particle size decreased, the $\mathrm{a}^{*}$ and $\mathrm{b}^{*}$ values decreased in the extrudates. As the screw speed of the extruder increased, the extrudates' $L^{*}$ value decreased, and the $b^{*}$ value increased. For amaranth, data analysis showed that as the moisture content increased, the expansion ratio of the extrudates decreased and their unit density and durability increased. As the particle size decreased, there was a decrease in the extrudates' $a^{*}$ and $b^{*}$ values. As the extruder's screw speed increased, the $L^{*}$ and $b^{*}$ values of the extrudates increased.

The information developed in this study will be useful for extrusion scale-up at food processing plants. Further study is needed, however, to determine how best to balance extrusion temperature, ingredient moisture, and other processing conditions in order to manufacture optimized snacks from both quinoa and amaranth.

\section{References}

Abalone, R., Cassinera, A., Gastón, A., \& Lara, M. A. (2004). Some physical properties of amaranth seeds. Biosystems Engineering, 89(1), 109-117. https://doi.org/10.1016/j.biosystemseng.2004.06.012

Ahamed, N. Thoufeel, Singhal, Rekha S., Kulkarni, Pushpa R., \& Pal, Mohinder. (1998). A lesser-known grain, Chenopodium quinoa: Review of the chemical composition of its edible parts. Food \& Nutrition Bulletin, 19(1), 61-70. https://doi.org/10.1177/156482659801900110

Becker, R., Wheeler, E. L., Lorenz, K., Stafford, A. E., Grosjean, O. K., Betschart, A. A., \& Saunders, R. M. (1981). A compositional Study of Amaranth Grain. Journal of Food Science, 46, 1175-1180. https://doi.org/10.1111/j.1365-2621.1981.tb03018.x

Bushway, A. A., Belyea, P. R., \& Bushway, R. J. (1981). Chia seed as a source of oil, polysaccharide, and protein. Journal of Food Science, 46, 1349-1350. https://doi.org/10.1111/j.1365-2621.1981.tb04171.x

Cheng, H., \& Friis, A. (2010). Modeling extrudate expansion in a twin-screw food extrusion cooking process through dimensional analysis methodology. Food and Bioproducts Processing, 88, 188-194. 
https://doi.org/10.1016/j.fbp.2010.01.001

Dogan, H., \& Karwe, M. V. (2003). Physicochemical properties of quinoa extrudates. Food Science and Technology International, 9(2), 101-114. https://doi.org/10.1177/1082013203009002006

Ilo, S., Liu, Y., \& Berghofer, E. (1999). Extrusion cooking of rice flour and amaranth blends. LWT- Food Science and Technology, 32, 79-88. https://doi.org/10.1006/fstl.1998.0497

Omary, M. B., Fong, C., Rothschild, J., \& Finney, P. (2012). Effects of germination on the nutritional profile of gluten-free cereals and pseudocereals: A review. Cereal Chem, 89(1), 1-14. https://doi.org/10.1094/CCHEM-01-11-0008

Riaz, M. N. (2012). Cereal extrusion technology for small food processing enterprises. Quality Assurance and Safety of Crops and Foods, 4, 136-158. https://doi.org/10.1111/j.1757-837X.2012.00168.x

Singh, S., Gamlath, S., \& Wakeling, L. (2007). Nutritional aspects of food extrusion: a review. International Journal of Food Science and Technology, 42, 916-929. https://doi.org/10.1111/j.1365-2621.2006.01309.x

Taverna, L. G., Leonel, M., \& Mischan, M. M. (2012). Changes in physical properties of extruded sour cassava starch and quinoa flour blend snacks. Ciencia E Tecnologia de Alimentos, 32(4), 826-834. https://doi.org/10.1590/S0101-20612012005000113

Vilche, C., Gely, M., \& Santalla, E. (2003). physical properties of quinoa seeds. Biosystems Engineering, 86(1), 59-65. https://doi.org/10.1016/S1537-5110(03)00114-4

Weber, Charles, W., Gentry, Howard, S., Kohlhepp, Edwin, A., \& McCrohan, Peter, R. (1991). The nutritional and chemical evaluation of Chia seeds. Ecology of Food and Nutrition, 26(2), 119-125. https://doi.org/10.1080/03670244.1991.9991195

\section{Copyrights}

Copyright for this article is retained by the author(s), with first publication rights granted to the journal.

This is an open-access article distributed under the terms and conditions of the Creative Commons Attribution license (http://creativecommons.org/licenses/by/4.0/). 